\title{
Coronary Artery Disease in Patients with Metabolic Syndrome
}

\author{
Aferdita Veseli ${ }^{1}$, Hortensia Gjergo ${ }^{2}$, Joana Seiti $^{3}$, Endri Hasimi $^{4}$, Edlira Rruci $^{5}$, Etleva Demiri ${ }^{6}$, \\ Prof. Elizana Petrela Zaimi ${ }^{7}$, Prof. Mimoza Lezha ${ }^{8}$

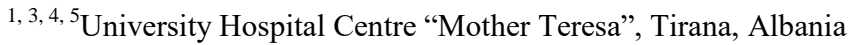 \\ ${ }^{2,8}$ Faculty of Medicine, Department of Cardiovascular Disease, Tirana, Albania \\ ${ }^{2,7}$ Faculty of Medicine, Department of Statistics, Tirana, Albania \\ ${ }^{6}$ Neostyle Clinic, Tirana, Albania
}

\begin{abstract}
Background: Metabolic syndrome (MS) has been reported to be associated with coronary artery disease (CAD). Objective: The purpose of this study was to evaluate the presence of CAD in patients with $M S$, and to compare each component of the syndrome in patients with and without CAD. Methods: 205 patients with MS who underwent elective coronary angiography were enrolled in the study. MS was defined according to National Cholesterol Education Program (NCEP)/Adult Treatment Panel III criteria. All patients were divided in two groups according to the presence of CAD. Results: The proportion of MS patients with CAD was significantly higher compared to those without CAD (72.68\% vs. $27.32 \%, p<0.001)$. Patients with CAD had higher levels of fasting blood glucose (78.50\% vs. $46.40 \%, p<0.001$ ) and lower levels of HDL-cholesterol (74.03\% vs. $25.97 \%$, $p<0.001$ ). There was no significant difference between the two groups regarding triglycerides levels $(75.80 \%$ vs. $80.40 \%$, p=0.493). Patients with CAD were less likely to have a high waist circumference $(67.10 \%$ vs. $84.00 \%, p=0.001)$ and to be hypertensive $(43.00 \%$ vs. $57.10 \%, p=0.049)$. Conclusion: MS and especially hyperglycemia and low HDL-cholesterol are associated with CAD. High waist circumference and hypertension were more prevalent in patients without $C A D$. There was no significant difference regarding elevated triglycerides in patients with and without CAD.
\end{abstract}

Keywords: Coronary Artery Disease, Metabolic Syndrome

\section{Introduction}

Coronary artery disease (CAD) represents a narrowing of coronary arteries, usually caused by atherosclerosis. It begins in the early youth [1]. Coronary artery disease is the most common cause of death in USA and Europe [2], [3]. While specific, mortality from ischemic heart disease in Albania is the highest in the Southeastern European region. Furthermore, Albania is the only country in the region that has experienced an increase in mortality from heart attack and cerebrovascular disease during the last two decades. The metabolic risk factors of ischemic heart disease in Albania are high systolic blood pressure, high total cholesterol, high body mass index, high fasting plasma glucose and low glomerular filtration rate [4].

Metabolic syndrome (MS) is a group of metabolic disorders such as glucose intolerance, obesity, hypertension, and dyslipidemia. The underlying disorder of this syndrome is insulin-resistance with the implication of exaggerated flux of fatty acids [5]. The metabolic risk factors influence atherosclerosis disease and are associated with a high risk for coronary artery disease. Patients with metabolic syndrome have a $30-40 \%$ probability of developing CAD within 20 years depending on the number of components participating in the syndrome [6]. The purpose of this study was to evaluate the presence of CAD in patients with MS, and the characteristics of each component of the syndrome in these patients with and without CAD.

\section{Methods}

\subsection{Subjects}

The study enrolled 205 patients with metabolic syndrome who underwent elective coronary angiography from November 2011 to February 2012 at "Mother Teresa" University Hospital Tirana, Albania. The metabolic syndrome patients fulfilled at least three of the following five criteria of this syndrome according to the National Cholesterol Education Program/Adult Treatment Panel III: 1- central obesity (WC>102 $\mathrm{cm}$ for males, $>88 \mathrm{~cm}$ for females), 2- elevated BP (systolic $\mathrm{BP} \geq 130 \mathrm{mmHg}$ or diastolic $\mathrm{BP} \geq 80 \mathrm{mmHg})$, 3- elevated $\mathrm{TG}(\geq 150 \mathrm{mg} / \mathrm{dL})$, 4 reduced HDL-cholesterol ( $<40 \mathrm{mg} / \mathrm{dL}$ for males, $<50 \mathrm{mg} / \mathrm{dL}$ for females), and 5- elevated FBG ( $\geq 110 \mathrm{mg} / \mathrm{dL})$. A previous diagnosis of type 2 diabetes mellitus is considered to be evidence of an elevated FBG.

\subsection{Biochemical assessment}

Fasting plasma blood samples were taken prior to elective coronary angiography. Serum lipid profile and fasting plasma glucose were analyzed in the laboratory of the University Hospital Centre "Mother Teresa",Tirana, Albania.

\subsection{Angiographic assessment}

Coronary angiography was performed via the femoral artery. The angiographic characteristics of all coronary lesions were described in the respective formulary and interpreted by interventional cardiologists. CAD was defined as $\geq 50 \%$ 


\section{International Journal of Science and Research (IJSR) \\ ISSN (Online): 2319-7064 \\ Index Copernicus Value (2015): 78.96 | Impact Factor (2015): 6.391}

luminal diameter stenosis of at least one major epicardial coronary artery.

The metabolic syndrome score was defined as the number of components present.

\section{Statistical Analysis}

- Data analysis was performed with SPSS statistical package, version 20 (Statistical Package for Social Sciences).

- Discrete data were presented in absolute value and percentage.

- Continuous data were presented as mean and standard deviation.

- Differences between groups, for discrete variables were performed using Chi-Square test.

- Differences between groups for continuous variables were performed using $\mathrm{t}$ test.

- A value of $\mathrm{p} \leq 0.05$ was considered as significant.

\section{Results}

205 patients with MS were enrolled in total in the study. 131 were males $(63.90 \%)$ and 74 were females $(36.10 \%)$. The mean age of patients was $59.99 \pm 8.98$ years, with a statistically significant difference $(\mathrm{p}<0.001)$ between patients with and without CAD. There were 149 patients $(72.68 \%)$ in total with CAD, out of which $107(71.80 \%)$ were males; thus CAD was significantly more common in men than in women $(\mathrm{P}<0.001)$. (Table 1) There was no significant statistically difference between the two groups regarding living area, religion and education.

Table 1: Demographic characteristics of the study population

\begin{tabular}{|c|c|c|c|c|}
\hline & $\begin{array}{c}\text { with CAD } \\
(\%)\end{array}$ & $\begin{array}{c}\text { without } \\
\text { CAD }(\%)\end{array}$ & $\begin{array}{c}\text { Total } \\
(\%)\end{array}$ & $\begin{array}{c}p \\
\text { value }\end{array}$ \\
\hline All MS Patients & $149(72.68)$ & $56(27.32)$ & $205(100 \%)$ & $<0.001$ \\
\hline Age <40 years old & $18(12.10)$ & $11(19.60)$ & $29(14.20)$ & 0.009 \\
$40-50$ years old & $53(35.60)$ & $24(42.90)$ & $77(37.60)$ & \\
$51-60$ years old & $53(35.60)$ & $16(28.60)$ & $69(33.70)$ & \\
61-70 years old & $25(16.80)$ & $5(8.90)$ & $30(14.60)$ & \\
\hline Gender & & & & $<0.001$ \\
Male & $107(71.80)$ & $24(42.90)$ & $130(63.90)$ & \\
\hline
\end{tabular}

\begin{tabular}{|c|c|c|c|c|}
\hline Female & $42(28.20)$ & $32(57.10)$ & $74(36.10)$ & \\
\hline Living area & & & & 0.611 \\
Urban & $112(75.20)$ & $44(78.60)$ & $156(76.10)$ & \\
Rural & $37(24.80)$ & $12(21.40)$ & $49(23.90)$ & \\
\hline Religion & & & & 0.333 \\
Muslim & $125(83.90)$ & $42(75.00)$ & $167(81.50)$ & \\
Christian & $24(16.10)$ & $14(25.00)$ & $38(18.50)$ & \\
\hline Education & & & & 0.795 \\
Elementary & $73(49.00)$ & $25(44.60)$ & $98(47.80)$ & \\
High school & $64(43.00)$ & $27(48.20)$ & $91(44.40)$ & \\
University & $12(8.10)$ & $4(4.10)$ & $16(7.80)$ & \\
\hline
\end{tabular}

The most frequent metabolic component in MS patients with CAD was reduced HDL-cholesterol (74.03\% vs. $25.97 \%$, $\mathrm{p}<0.001)$, and elevated fasting blood glucose $(78.50 \%$ vs. $46.40 \%, \mathrm{p}<0.001)$. There was no statistically significant difference between MS patients with or without CAD regarding elevated triglycerides levels $(75.80 \%$ vs. $80.40 \%$, $\mathrm{p}=0.493)$. Increased waist circumference was more prevalent in patients without $\mathrm{CAD}(84.00 \%$ vs. $67.10 \%, \mathrm{p}=0.001)$, but $62.5 \%$ of these patients were smokers. Although blood pressure was significantly more elevated in MS patients without CAD $(57.10 \%$ vs. $43.00 \%, \mathrm{p}=0.049), 85 \%$ of the patients with CAD had a history of hypertension. (Table 2)

Table 2: Frequency of each metabolic component in patients with and without CAD

\begin{tabular}{|c|c|c|c|c|}
\hline $\begin{array}{c}\text { Metabolic } \\
\text { components }\end{array}$ & $\begin{array}{c}\text { With } \\
\text { CAD } \\
(\%)\end{array}$ & $\begin{array}{c}\text { Without } \\
\text { CAD } \\
(\%)\end{array}$ & $\begin{array}{c}\text { Total } \\
(\%)\end{array}$ & $\begin{array}{c}P \\
\text { value }\end{array}$ \\
\hline $\begin{array}{c}\text { Low HDL- } \\
\text { cholesterol }\end{array}$ & $\begin{array}{c}134 \\
(74.03)\end{array}$ & $\begin{array}{c}47 \\
(25.97)\end{array}$ & $\begin{array}{c}181 \\
(88.29)\end{array}$ & $<0.001$ \\
\hline Elevated FBG & 117 & 26 & 143 & $<0.001$ \\
& $(78.50)$ & $(46.40)$ & $(69.80)$ & \\
\hline Elevated TG & 113 & 45 & 158 & 0.493 \\
& $(75.80)$ & $(80.40)$ & $(77.10)$ & \\
\hline Elevated BP & 64 & 32 & 96 & 0.049 \\
& $(43.00)$ & $(57.10)$ & $(46.80)$ & \\
\hline Increased WC & 100 & 47 & 147 & 0.001 \\
& $(67.10)$ & $(84.00)$ & $(71.70)$ & \\
\hline
\end{tabular}

Figure 1 presents the relation between $\mathrm{WC}$ and $\mathrm{CAD}$, according to gender. Males with decreased WC (26.80\%) and females with increased WC (34.60\%) had more CAD than males with increased WC $(37.10 \%)$ and females with decreased WC $(1.50 \%)$.

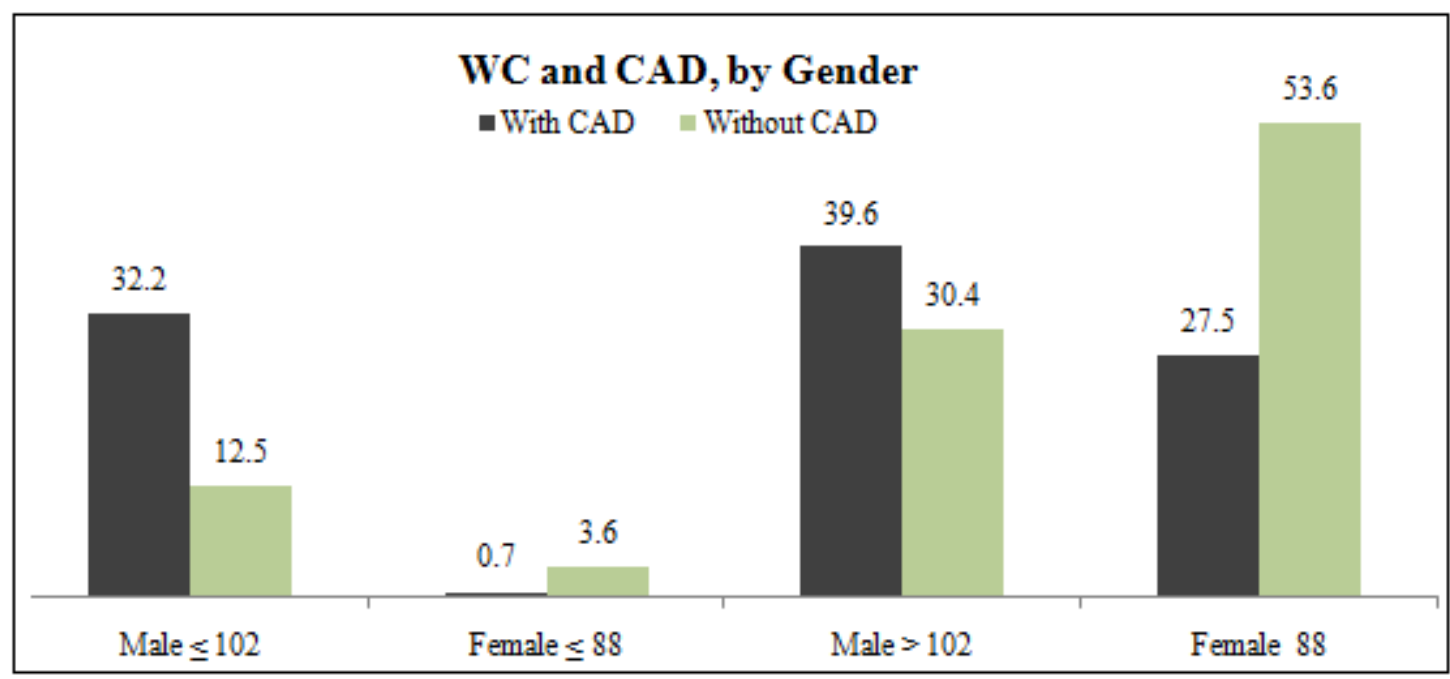

Figure 1: Relation between WC and CAD by Gender

Volume 6 Issue 7, July 2017 www.ijsr.net 


\section{International Journal of Science and Research (IJSR) \\ ISSN (Online): 2319-7064 \\ Index Copernicus Value (2015): 78.96 | Impact Factor (2015): 6.391}

Among the coronary risk factors, diabetes mellitus and smoking are more prevalent in patients with CAD. There is no significant statistically difference between the two groups regarding dyslipidemia, hypertension, and family history of CAD. (Table 3)

Table 3: Distribution of risk factors in MS patients with and without CAD

\begin{tabular}{|c|c|c|c|c|}
\hline Risk Factors & $\begin{array}{c}\text { with CAD } \\
(\%)\end{array}$ & $\begin{array}{c}\text { without } \\
\text { CAD }(\%)\end{array}$ & $\begin{array}{c}\text { Total } \\
(\%)\end{array}$ & $\begin{array}{c}p \\
\text { value }\end{array}$ \\
\hline Hypertension & $134(89.90)$ & $49(87.50)$ & $183(89.30)$ & 0.616 \\
\hline Diabetes Mellitus & $75(50.30)$ & $13(23.20)$ & $88(42.90)$ & $<0.001$ \\
\hline Smoking & $70(47.00)$ & $15(26.80)$ & $85(41.50)$ & 0.009 \\
\hline Dyslipidemia & $88(59.10)$ & $30(53.60)$ & $118(57.60$ & 0.479 \\
\hline Family History of CAD & $61(40.90)$ & $21(37.50)$ & $82(40.00)$ & 0.654 \\
\hline
\end{tabular}

We did not find any relation between the metabolic syndrome score and the presence of CAD. (Table 4)

Table 4: Frequency of Metabolic risk score

\begin{tabular}{|c|c|c|c|c|}
\hline $\begin{array}{c}\text { Metabolic } \\
\text { risk score }\end{array}$ & $\begin{array}{c}\text { With CAD } \\
(\%)\end{array}$ & $\begin{array}{c}\text { Without CAD } \\
(\%)\end{array}$ & $\begin{array}{c}\text { Total } \\
(\%)\end{array}$ & $\begin{array}{c}p \\
\text { value }\end{array}$ \\
\hline $3 / 5$ & $83(55.70)$ & $31(55.40)$ & $114(55.60)$ & 0.779 \\
\hline $4 / 5$ & $51(34.20)$ & $21(37.50)$ & $72(35.10)$ & \\
\hline $5 / 5$ & $15(10.10)$ & $4(7.10)$ & $19(9.30)$ & \\
\hline
\end{tabular}

Table 5 presents a summary of some demographic, anthropometric and biochemical parameters (continuous variables) regarding the presence of CAD. Patents with CAD were older, had elevated fasting glucose, and low HDLcholesterol statistically significant compared to those without CAD.

Table 5: Summary of some demographic, anthropometric and biochemical parameters

\begin{tabular}{|c|c|c|c|c|}
\hline & With CAD & Without CAD & Total & $\begin{array}{c}p \\
\text { value }\end{array}$ \\
\hline Age & $61.21 \pm 8.75$ & $56.73 \pm 8.88$ & $59.99 \pm 9.98$ & 0.001 \\
\hline FBG & $131.39 \pm 45.44$ & $106.02 \pm 31.61$ & $124.46 \pm 43.54$ & $<0.001$ \\
\hline WC & $103.00 \pm 11.23$ & $105.77 \pm 10.99$ & $103.76 \pm 11.21$ & 0.115 \\
\hline $\begin{array}{c}\text { Total } \\
\text { Cholesterol }\end{array}$ & $180.73 \pm 57.86$ & $193.42 \pm 55.19$ & $184.20 \pm 57.29$ & 0.158 \\
\hline $\begin{array}{c}\text { HDL- } \\
\text { Cholesterol }\end{array}$ & $34.76 \pm 6.70$ & $37.85 \pm 7.72$ & $35.60 \pm 7.11$ & 0.005 \\
\hline $\begin{array}{c}\text { LDL- } \\
\text { Cholesterol }\end{array}$ & $106.40 \pm 46.25$ & $106.64 \pm 38.13$ & $106.47 \pm 44.09$ & 0.972 \\
\hline Triglycerides & $214.60 \pm 120.92$ & $213.97 \pm 107.4$ & $214.43 \pm 117.13$ & 0.972 \\
\hline
\end{tabular}

\section{Discussion}

The purpose of our study was to evaluate the presence of $\mathrm{CAD}$ in patients with MS and to compare each component of the syndrome in these patients with and without CAD.

We use the ATP III definition criteria to diagnose metabolic syndrome [7]. Waist circumference is the first criteria in this definition that reflects abdominal obesity as the major contributor of the metabolic syndrome. In our study we found that waist circumference is decreased in patients with $\mathrm{CAD}$. These patients were smokers in a greater percentage than the other group without $\mathrm{CAD}$, and probably the reason of this finding is the effect of smoking on increasing whole body metabolism. In our knowledge there is no other study which has reached such a conclusion. There is a publication showing that $\mathrm{WC}$ and waist-to-hip ratio is in normal range in patients with CAD, but not decreased [8].

Metabolic syndrome is known as insulin resistance syndrome [9]. Insulin resistance manifests as glucose intolerance, and when glucose intolerance leads to high glucose levels, this is a risk factor for $\mathrm{CAD}$. The first prospective observation that found out the role of hyperglycemia in CAD was the Framingham Study which showed that the incidence of cardiovascular disease is two-to three folds higher in diabetic patients [10]. Fasting blood glucose in our study was higher in patients with CAD.

Dyslipidemia in serum lipid profiles presented as raised triglycerides and low HDL-cholesterol, raised total cholesterol and raised LDL-cholesterol. We found that the most frequent metabolic component present in our study was low HDL-cholesterol which is in concordance with other studies showing that reduced HDL is the most important lipid fraction affecting CAD [11]. Triglycerides, LDL cholesterol and total cholesterol had no statistically differences between patients with and without CAD. In other studies, elevated triglycerides correlate with CAD [12], [13].

As we have shown above, hyperglycemia and low HDLcholesterol correlated with coronary artery disease, which has been noted as well in other studies [14]-[17]. Elevated blood pressure correlates with obesity and occurs in insulinresistant patients. Hypertension is listed as a risk factor component of the metabolic syndrome, although probably less important than the others [18]. In our study hypertension was more prevalent in patients without coronary artery disease. The major number of patients with high blood pressure had a history of hypertension and was under treatment. In other studies high blood pressure has correlated with coronary artery disease [19]-[22].

\section{Conclusion}

In our study MS and especially hyperglycemia and low HDL-cholesterol were associated with CAD. High waist circumference and hypertension were more prevalent in patients without CAD. There was no significant difference regarding elevated triglycerides in patients with and without CAD.

\section{Limitations}

The number of patients was relatively small. The group without coronary artery disease is less healthy than the general population because they were hospitalized for a reason.

\section{References}

[1] Coronary Artery Disease, my.clevelandclinic.org

[2] US National Center for Health Statistics. National Vital Statistics Reports. Deaths: preliminary data for 2010.2012. Available at http://www.cdc.gov/nchs/data/nvsr/nvsr60 04.pdf

[3] Nicols M, Townsend N, Scarborough P, Rayner M. European cardiovascular disease statistics, 2012

\section{Volume 6 Issue 7, July 2017 www.ijsr.net}




\section{International Journal of Science and Research (IJSR) \\ ISSN (Online): 2319-7064}

Index Copernicus Value (2015): 78.96 | Impact Factor (2015): 6.391

edition.2012.

Available

http://www.ehnheart.org/cvd-statistics.html

[4] Ischemic Heart disease in Albania- Stats, Demographics Affected, GBD global- burden - disease 2010. Albanian Public Health Institute, the National Health Report 2014

[5] Robert H Eckel, Scot M Grundy, Poul Z Zimmet. The metabolic syndrome. Lancet 2005; 365: 1415-28

[6] Wannamethee SG, Shaper AG, Lennan L et al. Metabolic Syndrome vs Framingham Risk Score for prediction of coronary artery disease, stroke, and type 2 diabetes mellitus. Ach Intern Med. 2005; 165 (22): 2644-265

[7] Third report of the National Cholesterol Education Program (NCEP) expert panel on detection, evaluation, and treatment of high blood cholesterol in adults (Adult Treatment Panel III). Final report. Circulation. 2002; 106:3143-3421

[8] Enas EA, Mohan V, Deepa M, Farooq S, Pazhoor S, Chennikkara $H$. The metabolic syndrome and dyslipidemia among Asian Indians: A population with high rates of diabetes and premature coronary artery disease. J Cardiometab Syndr 2007; 2 : 267-75)

[9] DeFronzo RA, Ferrannini E. Insulin Resistance. A multifaceted syndrome responsible for NIDDM, obesity, hypertension, dyslipidemia, and atherosclerotic cardiovascular disease. Diabetes care 1991; 14: 173-94

[10] Kannel WB, McGee DL: Diabetes and cardiovascular risk factors in the Framingham study. JAMA 38: 46-51, 1978

[11] Jenkins PJ, Harper RW, Nestel PJ. Severity of coronary atherosclerosis related to lipoprotein concentration. $\mathrm{Br}$ Med J 1978; 2:388-391

[12] Cynthia J. Girman, DRPH, Thomas Rhodes, MSPH, Michele Mercuri, MD, PhD, Kalevi Pyörälä, MD, John Kjekshus, MD, Terje R. Pedersen, MD, Polly A. Beere, MD, Antonio M. Gotto, MD, and Michael Clearfield, $\mathrm{DO}$, for the $4 \mathrm{~S}$ Group and the AFCAPS/TexCAPS Research Group. The Metabolic Syndrome and Risk of Major Coronary Events in the Scandinavian Simvastatin Survival Study (4S) and the Air Force/Texas Coronary Atherosclerosis Prevention Study (AFCAPS/TexCAPS). The American Journal of Cardiology Vol. 93 January 15, 2004

[13] Naveed Sattar, MD; Allan Gaw, MD; Olga Scherbakova, MSc; Jan Ford, PhD; Denis St.J. O'Reilly, MD; Steven M. Haffner, MD; Chris Isles, MD; Peter W. Macfarlane, DSc; Chris J. Packard, DSc; Stuart M. Cobbe, MD; James Shepherd, MD. Metabolic Syndrome With and Without C-Teactive Protein as e Predictor of Coronary Heart Disease and Diabetes in the West of Scotland Coronary Prevention Study. Circulation. 2003; 108:414-419

[14] Noha Hassanin, Soliman Gharib, Mohammed Z. El Ramly, Mohammed Abdel Meged and Ahmed Makram. Metabolic syndrome and coronary artery disease in young Egyptians presenting with acute coronary syndrome. Kasr Al Ainy Medical Journal 2015, 21:27-33

[15] Takatoshi Kasai, Katsumi Miyauchi, Naozumi Kubota, Hiroshi Tamura, Takahiko Kojima, Ken Yokoyama, Takeshi Kurata, Hiroyuki Daida. The relationship between the metabolic syndrome defined by vatious criteria and the extend of coronary artery disease. Atherosclerosis 197 (2008) 944-950

[16] Jong-Youn Kim, Hee-Sun Mun, Byoung Kwon Lee, Seong Bo Yoon, Eui-Young Choi,pil-Ki Min, YoungWon Yoon, Bum-Kee Hong, Se-Joong Rim, and Hyuck Moon Kwon. Impact of Metabolic Syndrome and Its Individual Components on the Presence and Severity of Angiographic Coronary Artery Disease.Yonsei Med J 51(5):676-682,2010

[17] Carlos Iribarren, MD, MPH, PHP, Alan S. Go, MD, Gail Husson, MPH, MED, Stephen Sidney, MD, MPH, Joan M. Fair, ANP, PHD, Thomas Quertermous, MD, Mark A. Hlatky, MD, Stephen P. Fortmann, MD. Metabolic Syndrome and Early-Onset Coronary Artery Disease. Journal of the American College of Cardiology. Vol. 48, No 9, 2006

[18] Scott M. Grundy, MD, PhD; H. Bryan Brewer, Jr, MD; James I. Cleeman; Sidney C. Smith, Jr, MD; Claude Lenfant, MD; for the Conference Participants. Definition of Metabolic Syndrome. Report of the National heart, Lung and Blood Institute/American heart Association Conference on Scientific Issues Related to Definition. Circulation. 2004; 109:433-438

[19] Shin-Eui Yoon, Sung Gyun Ahn, Jang-Young Kim, Jin-Sun Park, Joon-Han Shin, Seung-Jea Tahk, SuKyeong Lee, Tae-Jin Kim and $\mathrm{Na}$ Han, Differential Relationship between Metabolic Syndrome Score and Severity of Coronary Atherosclerosis as Assessed by Angiography in Non-Diabetic and Diabetic Korean Population. J Korean Med Sci 2011; 26: 900-905

[20] Jong-Youn Kim, Hee-Sun Mun, Byoung Kwon Lee, Seong Bo Yoon, Eui-Young Choi,pil-Ki Min, YoungWon Yoon, Bum-Kee Hong, Se-Joong Rim, and Hyuck Moon Kwon. Impact of Metabolic Syndrome and Its Individual Components on the Presence and Severity of Angiographic Coronary Artery Disease.Yonsei Med J 51(5):676-682,2010

[21] Carlos Iribarren, MD, MPH, PHP, Alan S. Go, MD, Gail Husson, MPH, MED, Stephen Sidney, MD, MPH, Joan M. Fair, ANP, PHD, Thomas Quertermous, MD, Mark A. Hlatky, MD, Stephen P. Fortmann, MD. Metabolic Syndrome and Early-Onset Coronary Artery Disease. Journal of the American College of Cardiology. Vol. 48, No 9, 2006

[22] Carlos Iribarren, MD, MPH, PHP, Alan S. Go, MD, Gail Husson, MPH, MED, Stephen Sidney, MD, MPH, Joan M. Fair, ANP, PHD, Thomas Quertermous, MD, Mark A. Hlatky, MD, Stephen P. Fortmann, MD. Metabolic Syndrome and Early-Onset Coronary Artery Disease. Journal of the American College of Cardiology. Vol. 48, No 9, 2006

\section{Author Profile}

Aferdita Veseli received her M.D. degree from the Faculty of Medicine, University of Tirana, Albania in 1997. During 1998-2002 she worked as a General Practitioner (GP) in the Polyclinic No. 10 in Tirana, Albania. She did her specialization in Cardiology during 2002-2006 in the Faculty of Medicine, University of Tirana. During 2007-2011 she worked as a cardiologist at the Polyclinic No. 9 and from 2011 she works as a cardiologist at the Cardiac Surgery Clinic in the University Hospital Center "Mother Teresa", Albania.

\section{Volume 6 Issue 7, July 2017 www.ijsr.net}

